\title{
A STRUCTURAL EQUATION MODEL OF COMMUNICATIVE COMPETENCE IN FILIPINO
}

\author{
Arcel W. Gacasan, PhD $^{1}$, Elleine Rose A. Oliva, EdD ${ }^{2}$
}

Article DOI: https://doi.org/10.36713/epra9603

DOI No: 10.36713/epra9603

\begin{abstract}
This study aims to determine the model more appropriate for teachers 'communicative ability. This study focuses on the relationship between teachers 'beliefs, instructional practices, and teachers 'oral skills related to teachers' communicative ability in Filipino. The research employed quantitative design and structural equation modeling. Following an expert's validation and approval of the questionnaire, tabulation, analysis, and data translation were immediately performed. Additionally, performing data interpretation using the mean, standard deviation, Pearson product-moment correlation coefficient, multiple regression, and structural equation model. Around 400 participants were recruited using data from Region XI's ten public secondary school divisions. The study discovered that all independent and non-independent variables and their indicators achieved the highest level of descriptiveness. Thus, a significant correlation exists between teachers' beliefs, instructional practices, oral proficiency, and communicative competence. The study's findings indicate that the fifth model is more appropriate for teachers' communicative competence in the Filipino language.
\end{abstract}

KEYWORDS: education, communicative competence, instructional practices, belief, oral proficiency, regression, structural model, Philippines

\section{INTRODUCTION}

There is no denying that it is critical to have effective communication skills because they serve as a conduit for mutual understanding. However, there will always be a challenge in developing teachers' communicative competence in education. Fluency in communication refers to an understanding of the grammar of syntax, morphology, phonology, and social knowledge about how and when to use words appropriately (Yufrizal 2017). According to one study, Kenya faces a problem in which most students are unable to communicate and cannot speak English directly without using code-switching. Additionally, the study discovered differences in teachers' use of activities within the classroom, such as discussion, which was the most frequently used strategy, compared to oral tests. Code-switching frequently occurs as a result of students' inability to communicate effectively. After all, teachers do not use the actual language spoken in the classroom, contributing to the students' low communicative ability. (2014) (Gudu).

The ability to communicate implies that communication is a critical aspect of a person's life. This ability can be expressed verbally, in writing, or even non-verbally. It is an all-inclusive term that refers to language knowledge and the ability to use it in real-world situations to meet communication requirements. According to numerous researchers, language is a mode of communication that consists of four fundamental skills: listening, speaking, reading, and writing. To acquire these language skills, one must understand the grammar rules and practice them until they become second nature. When an individual acquires language skills and can apply them effectively and appropriately in the context in which he or she is working, we can say that the individual has attained the required level of communicative ability. (2018) (Ahmer and Pawar).

Teachers' beliefs are critical components of language learning. According to one study, teachers' beliefs are disregarded, their teaching methodology is frequently impacted. The teacher who adopts new reforms or instructional methods most likely simplifies teaching. Just as in Iran, where the process of developing new teaching methods has been neglected, teaching grammar has become the norm for many years. Teachers' beliefs are potentially beneficial for successful language teaching, particularly in developing a student's communicative abilities (Tootkaboni, 2019). There is no definitive structural standard model for communicative ability at the local level. The researcher has not yet come across a study examining teachers' beliefs, instructional practices, oral abilities, and model approaches to communicative ability in the Philippines' Region XI. Its content implies that teachers' beliefs, instructional practices, and oral skills can serve as a model approach to communicative competence, providing readers with the knowledge and a focus for learning and possibly facilitating the development of planned interventions to foster the ability to communicate with each individual for the benefit of society, school, teachers, and students.

In this regard, the researcher will diligently conduct research to ascertain the source of the existing problem and thus address it immediately. 


\section{RESEARCH OBJECTIVES}

This study aimed to develop the most appropriate model on communicative competence in the Filipino language to beliefs, instructional practices, and oral proficiency. In this regard, the researcher wants to answer the following specific objective:

1. Determine the level of belief of Filipino teachers in secondary schools based on:

1.1 role and contribution of students;

1.2 accuracy to inaccuracy and analysis;

1.3 role and importance of grammar;

1.4 teacher role;

1.5 perform in the native language; at

1.6 perform in group or pair work.

2. Determine the level of instructional practices of Filipino teachers in secondary schools based on:

2.1 teaching strategies focused on facilitating students' comprehension;

2.2 strategies based on group work and oracy skills; and

2.3 teaching strategies to develop literacy skills.

3. Determine the level of oral proficiency of Filipino teachers in secondary schools based on:

3.1 comprehension;

3.2 fluency;

3.3 vocabulary;

3.4 pronunciation;

3.5 grammar;

3.6 classroom teaching; at

3.7 non-verbal communication

4. Determine the level of communicative competence in the Filipino language based on:

4.1 classroom interaction on students' communicative competence;

4.2 teaching methods enhance communicative competence; and

4.3 students' exposure to various linguistic environmental and speaking skills.

5. Determine the significant relationship between teachers' beliefs, instructional practices, oral proficiency, and communicative competence in the Filipino language.

6. Identify the significant effect of beliefs, instructional practices and oral proficiency on communicative competence in the Filipino language.

7. Know the model best suited to communicative competence in Filipino.

\section{HYPOTHESIS}

The null hypothesis of the study was developed and tested based on a 0.05 level of significance in which:

1. There is no significant relationship between:

1.1 teachers' beliefs;

1.2 instructional practices and

1.3 teachers' oral proficiency

2. No variable significantly affects communicative competence

3. There is no model best suited to the communicative competence

\section{METHODOLOGY}

The design of this study is a quantitative research method of data collection that describes the relationship between a number to anything that can be quantified across multiple times or conditions. This design deals with quantifying and analyzing variables to get results (Leedy \& Omrod, 2001). Moreover, this study will use causal research design as a methodology because of the types of variables measured. Sequentially, the casual method is used in this study to find relationships between independent and dependent variables after an action or event has already occurred (Creswell 2013). Thus, establishing a predictive relationship is a descriptive correlational research design characteristic. It uses two or more data sets to evaluate the significant correlation of each variable.

Additionally, this study focused on using the data to hit models in teachers' beliefs, instructional practices, oral proficiency, and communicative competence in the Filipino language. Consequently, a causal model was developed to describe the relationship of the overt and covert variables of the study (Hatami 2018). In addition, the Structural Equation Model (SEM) can be used to strengthen the integrity of the output obtained by emphasizing the following procedures: defining the model, collecting data, estimating what to be modeled, modeling analysis, and possibly making changes to the study's actual development in response to the study's overall result of the teacher's response to objectives.

\section{SAMPLING DESIGN}

The study's design is based on a quantitative research method of data collection that accurately describes the study's findings. A numerical relationship can be quantified through a systematic examination of various circumstances. To assess the 
level of communicative competence with 400 teachers teaching Filipino in secondary public schools of Davao Region from grade seven to ten of Junior High School in the academic year 2020-2021.

As a result, this study is a structural model with various fit indices that account for the effect of sample size. As with other statistical techniques, SEM requires a sufficient sample size to generate reliable estimates. Hair et al. (2008) concur, recommending a sample size of at least 200 but no more than 400. As a result, it can be concluded that SEM research studies require a minimum and maximum sample size of 200 and 400, respectively. However, (Karagoz 2016) asserted that the structural model is superior to other methods for theory testing.

Simultaneously, to ensure that the required number of participants from various divisions in Region XI is obtained, the number of participants in each division for the academic year 2020-2021 was calculated using Sloven's formula with a 0.05 level of significance, using stratified random sampling with a total of 400 respondents. Stratified random sampling is a technique that divides the population into strata (or subgroups) and draws a random sample from each subgroup. Its purpose is to ensure that each stratum is represented adequately (Johnson \& Christensen, 2004).

Thus, the researcher considers the 400 study participants who responded to a survey questionnaire regarding the use of scientific processes in participant selection. Respondents were chosen using a stratified random sampling technique to ascertain the number of teachers in each public secondary school and junior high school in Region XI. This method ensures that all population members have an equal chance of being selected as the sample unit (David 2015). Additionally, Baridalyne (2012) confirmed that results from stratified random sampling are representative of the entire population. The data is drawn randomly from a number table or manually created a list of numbers.

As a result, the study's participants will range from grade seven to ten junior high school teachers in public secondary schools in Region XI who are currently teaching Filipino in the school year 2020-2021 under the Department of Education.

\section{STATISTICAL DESIGN}

For a broader and meaningful interpretation and analysis of the data, the researcher used the following statistics:

Mean. To determine the level of teachers' belief; know the level of instructional practices, determine the level of oral proficiency to develop communicative competence in the Filipino language.

Standard Deviation. It is a tool used to measure and determine the distribution of frequency.

Pearson Product Moment Correlation. It determines the importance of the relationship between teachers 'beliefs, instructional practices, oral proficiency, and communicative competence in the Filipino language.

Multiple Regression. It cultivates significant predictors of communicative competence in the Filipino language.

Structural Equation Model. It was used to obtain the best and most appropriate model. In the analysis, the researcher suggested a boundary value of 0.05 . At the same time, Ullman (2006) used 0.45 to boost the culture of construction safety. Therefore, the essence of the test, according to (Bentler and Savalei 2010), is to ensure the removal of properties with a low relationship with characteristics and other factors hidden in the last Structural Equation Model. The cut-off value affects the sample size, but the range of 0.45 to 0.50 is appropriate if considered. Additionally, this tool ascertains the best model appropriate to organizational essence.

The goodness of Fit Statistics, the Alternative Model through Analysis of Moment Structure (AMOS) was used. According to Blunch (2007), it is used to obtain the appropriate learning model; all the values given in the indices are included in each criterion.

- $\quad$ Chi Square/Degree of Freedom (CMIN/DF)

- P Value

- $\quad$ Normative Fit Index (NFI)

- $\quad$ Comparative Fit Index (CFI)

- Goodness of Fit Index (GFI)

- Tucker-Lewis Index

- $\quad$ Root Mean Square Error of Approximation (RMSEA)

- $\quad$ P close

$$
\begin{aligned}
& 0<\text { value }<2 \\
& >0.05 \\
& >0.95 \\
& >0.95 \\
& >0.95 \\
& >0.95 \\
& <0.05 \\
& >0.50
\end{aligned}
$$

\section{GEOGRAPHICAL AREA}

Davao Region, where the public schools to be researched is located. The Davao Region is located in the Southeastern part of the island of Mindanao, surrounding the Davao Gulf. It borders the northern provinces of Surigao del Sur, Agusan del Sur and Bukidnon. To the east, it is bordered by the Philippine Sea and in the western provinces of Central Mindanao. The Davao Region area faces Micronesia in the South Pacific Ocean to the east and Eastern Indonesia by the Celebes Sea to the south within the broader geographical context.

This study aimed to improve the communicative competence of teachers in grades seven to ten of Region XI Junior High Schools in the Filipino language. To this end, in the academic year 2020-2021, to assess the level of communicative competence in the Filipino language among 400 study participants in grades seven to ten of Junior High School. On the other hand, this study is a structural equation model with multiple indices affecting sample size. However, some researchers believe that the required sample size for structural equation models should be 200 and between 200 and 500. (Celik and Yilmaz 2013). However, (Karagoz 2016) stated that the structural model is more suitable for theory testing than other methods because it correlates with the data from the theoretical model. 
Simultaneously, in order to obtain an accurate count of participants from each division in Region XI, Sloven's formula is used to determine the number of participants in each division who are currently teaching Filipino in the academic year 2020-2021 using stratified random sampling of 400 participants with a 0.05 level of significance. Additionally, stratified random sampling is a technique that divides the population into strata (or subgroups) and draws a random sample from each subgroup. Its purpose is to ensure that each stratum is represented adequately (Creswell, 2002; Johnson \& Christensen, 2004). Thus, the researcher considers the 400 respondents to the survey by the scientific process used to select participants. Thus, participants in the study will be grade seven to ten teachers of Junior High schools in public secondary schools in Region XI for the academic year 2020-2021, using a stratified random sampling technique. As a result, selected participants can respond to the questionnaire if they provide the necessary study data.

\section{RESULTS}

This section presents data and generated results from participants 'responses to teachers' beliefs, instructional practices, and oral proficiency: a structural equation model to communicative competence in the Filipino language. Thus, the collected data have been thoroughly analyzed from variables such as the belief that evaluate the level of indicators such as role and contribution of learners, error correction and assessment, role and importance of grammar, teacher role, role of the learners native language, role in group or pair work: also evaluate the level of indicators derived from variable instructional practices comprised of instructional strategies focused on teaching strategies focused on facilitating students' comprehension, strategies based on group work and oracy skills, teaching strategies to develop literacy skills; the level of the indicator from variable oral proficiency will also assess the level of comprehension, fluency, vocabulary, correct pronunciation, grammar, classroom teaching, non-verbal communication as well as non-variable communicative competence to assess the level of following correlation indicator in the classroom interaction of students communicative competence, teaching methods enhance communicative competence, students exposure to various linguistic environmental and speech skills.

\section{Level of Teachers' Beliefs}

Table 1 depicts the first variable, which is the level of beliefs, consisting of six indicators: and with a total of twentyeight (28) statements, participants achieved a very high descriptive level that proved that teachers belief was always seen concerning the role and contribution of the learners, error correction and assessment, role and importance of grammar, teacher role, the role of the learner's native language and role in group or pair work indicators all achieving a total standard deviation (SD) of 0.39 and a total mean score of 4.34 .

Table 1

Level of Belief of Filipino Teachers in Secondary Schools

\begin{tabular}{lccc} 
Indicator & SD & Mean & Score Descriptive Level \\
\hline Role and Contribution of the Learners & 0.53 & 4.26 & Very High \\
Error Correction and Assessment & 0.60 & 4.06 & High \\
Role and Importance of Grammar & 0.54 & 4.21 & Very High \\
Teacher Role & 0.43 & 4.66 & Very High \\
Role of the Learners Native Language & 0.62 & 4.39 & Very High \\
Role in Group/Pair Work & 0.51 & 4.44 & Very High \\
Total & $\mathbf{0 . 3 9}$ & $\mathbf{4 . 3 4}$ & Very High \\
\hline
\end{tabular}

It can be seen from the data that the first indicator in teachers' belief, the role of the contribution of the learners, achieved a very high descriptive level showing that always observed and obtained a standard deviation of 0.53 with a mean score of 4.26 . However, the second indicator received a high descriptive level, indicating that it was frequently detected with a standard deviation of 0.60 with a mean score of 4.06. Thus, the third indicator, role and importance of grammar received a very high descriptive level showing a standard deviation of 0.54 with a mean score of 4.21 . However, the fourth indicator, teacher role, was a very high descriptive level indicating that it was consistently recognized, with a standard deviation of 0.43 with a mean score of 4.66. On the other hand, the fifth indicator of the learner's native language role was very high descriptive, showing that it was always detected and obtained a standard deviation of 0.62 with a mean score of 4.39 . However, with a standard deviation of 0.51 with a mean score of 4.44 , the sixth indicator of role in group or pair work had a very descriptive level, indicating that it was always observed.

The findings of this study corroborate Zheng's (2009) observation that teachers' beliefs are critical concepts for comprehending teachers' thought processes, teaching methods, and teaching-learning. Teacher beliefs are critical components of teacher education because they assist teachers in developing their thought and principles. Additionally, the study supported (Li, 2012; Pajares, 1992) that their beliefs influence teachers' classroom practices and professional development.

\section{Level of Instructional Practices}

In this part, we can see the result of the study conducted about the level of instructional practices of teachers were presented in the second table are three indicators: and eighteen (18) statements that the result of the total standard deviation (SD) is 0.33 and has a mean score of 4.76 which obtained the descriptive level very high confirming that instructional practices always observed. 
Table 2

Level of Instructional Practices of Filipino Teachers in Secondary

\begin{tabular}{lccc}
\hline Indicator & SD & Mean & Descriptive Level Score \\
\hline $\begin{array}{l}\text { Teaching strategies focused on facilitating } \\
\text { students' comprehension }\end{array}$ & 0.39 & 4.73 & Very High \\
Strategies Based on Group Work & 0.36 & 4.78 & Very High \\
and Oracy Skills & & & \\
Teaching Strategies to develop literacy skills & 0.38 & 4.79 & Very High \\
Total & $\mathbf{0 . 3 3}$ & $\mathbf{4 . 7 6}$ & Very High \\
\hline
\end{tabular}

Table 2 shows the result of the survey concerning the first indicator. A teaching strategy focused on facilitating students' comprehension, with a standard deviation (SD) of 0.39 and a mean score of 4.73 , the corresponding descriptive level is very high and consistently observed. Meanwhile, the second indicator related to a strategy based on group work and oracy skills shows a standard deviation (SD) of 0.36 and has a mean score of 4.78 , a very high descriptive level confirming that it was consistently recognized. However, the third indicator, teaching strategies to develop literacy skills, achieved a very high descriptive level showing that it was always observed and obtained a standard deviation (SD) of 0.38 and had a mean score of 4.79 .

These findings support Web et al., 2014) .'s study, which found that training teachers in the use of instructional moves aimed at increasing student talk and increasing student use of reasoned argumentation. A good example is prompting students to provide reasons and evidence, asking them to clarify their ideas, focusing attention on them, and challenging them with new ideas. This increased student elaboration of their ideas and generation of evidence-based arguments.

\section{Level of Oral Proficiency}

Table 3 The level of oral proficiency of teachers consisting of seven indicators with a total of twenty-nine (29) statements. Thus, the result of this variable has obtained a very high descriptive level depicting that it was always observed. As a result, the standard deviation is 0.31 and a mean score of 4.76 .

Table 3

Level of Oral Proficiency of Filipino Teachers in Secondary Schools

\begin{tabular}{lccc}
\hline Indicator & SD & Mean & Descriptive Level Score \\
\hline Comprehension & 0.34 & 4.84 & Very High \\
Fluency & 0.43 & 4.71 & Very High \\
Vocabulary & 0.41 & 4.72 & Very High \\
Correct pronunciation & 0.37 & 4.80 & Very High \\
Grammar & 0.41 & 4.75 & Very High \\
Classroom Teaching & 0.37 & 4.77 & Very High \\
Non-verbal Communication & 0.40 & 4.77 & Very High \\
& & & \\
Total & $\mathbf{0 . 3 1}$ & $\mathbf{4 . 7 6}$ & Very High \\
\hline
\end{tabular}

The result of each indicator is reflected in table 3. The first indicator, related to comprehension, achieved a very high descriptive level, which showed that comprehension was always observed and obtained a standard deviation of 0.34 with a mean score of 4.84. The second indicator related to fluency had a standard deviation (SD) of 0.43 and a mean score of 4.71 , with the descriptive level being the very high means that it was always detected. The third indicator related to vocabulary has a standard deviation (SD) result of 0.41 and has a mean score of 4.71, and is very high descriptive and always recognized. The third indicator, vocabulary, had a standard deviation (SD) result of 0.41 and a mean score of 4.72 , which obtained the very high descriptive level showing that it was always observed. The fourth indicator, correct pronunciation, the standard deviation (SD) of 0.37 , and a mean score of 4.80 can be observed and have a very high descriptive level. The fifth indicator related to grammar obtained a standard deviation (SD) of 0.41 and with a mean score of 4.75 obtained the very high descriptive level showing that it was always observed. The sixth indicator related to classroom instruction had a standard deviation (SD) of 0.37 and a mean score of 4.77 , which got the very high descriptive level, and the last indicator related to non-verbal communication got the standard deviation (SD) of 0.40 and with a mean score of 4.77 obtained the very high descriptive level imposed those non-verbal communications are always observed.

The study conducted by Khan et al. (2017) also supported the notion that a teacher's communication skills play a significant role in students' academic success. As a result, a teacher must demonstrate effective communication skills when instructing students. Additionally, Maley (2009) asserts that teachers with strong communication skills are more likely to have students who speak, bolstering the result.

\section{Level of Communicative Competence in the Filipino Language}

The level of communicative competence in the Filipino language with six indicators consisting of eleven (11) statements achieved descriptive very high level, always showing and obtained a total standard deviation (SD) of 0.45 and has a mean of 4.5 . 
Table 4

Level of Communicative Competence in the Filipino Language

\begin{tabular}{|c|c|c|c|}
\hline Indicator & $S D$ & Mean & Descriptive Level Score \\
\hline Classroom Interaction on Students & 0.41 & 4.73 & Very High \\
\hline Communicative Competence & & & \\
\hline Teaching Methods Enhance & 0.40 & 4.67 & Very High \\
\hline Communicative Competence & & & \\
\hline Students Exposure to various Lingu & & & \\
\hline Environmental and Speech Skills & 0.92 & 4.14 & Very High \\
\hline Total & 0.45 & 4.51 & Very High \\
\hline
\end{tabular}

Thus, the first indicator, classroom interaction on students' communicative competence, achieved a very high descriptive level showing that it was always visible and obtained a standard deviation (SD) of 0.41 and had a mean score of 4.73 . Nevertheless, the second indicator, teaching methods enhance communicative competence, achieved a very high descriptive level showing a standard deviation (SD) of 0.40 and a mean score of 4.67. However, with a standard deviation (SD) of 09.92 and a mean score of 4.14, the third indicator of students' exposure to various linguistic environmental and speech skills had a very high descriptive level, indicating that it was always observed.

The study's findings corroborate Akinwamide and Akande's (2019) findings that teachers are familiar with various teaching methods and agree that utilizing a variety of teaching methods can help students improve their communicative competence. Despite their awareness of the importance of utilizing various instructional methods, most teachers fail to vary their instructional methods and incorporate activities that promote classroom communication.

Table 6

Significant Influence of Teachers 'Beliefs, Instructional Practices and Oral Proficiency on Communicative Competence.

Communicative Competence.

\begin{tabular}{|c|c|c|c|c|c|}
\hline Exogenous Variables & & $B$ & $\beta$ & $t$ & Sig. \\
\hline Constant & & .383 & & 1.351 & .178 \\
\hline Beliefs of the Teachers & & .466 & .409 & 9.000 & .000 \\
\hline Instructional Practices & & .223 & .162 & 2.018 & .044 \\
\hline Oral Proficiency & & .219 & .153 & 1.847 & .065 \\
\hline $\mathrm{R}$ & .617 & & & & \\
\hline $\mathrm{R}^{2}$ & .381 & & & & \\
\hline$\Delta \mathrm{R}$ & .376 & & & & \\
\hline $\mathrm{F}$ & 81.172 & & & & \\
\hline$\rho$ & .000 & & & & \\
\hline
\end{tabular}

This table emphasizes that the result of the collected data reflected those teachers' beliefs had standardized and unstandardized coefficients of .466 and .409 , $\mathrm{t}$-value of 9.000 , and p-value of .000 (Significant). Instructional practices have standardized and unstandardized coefficients of .223 and .162, t-value of 2.018, and p-value of .044 (significant); and oral proficiency of teachers with standardized and unstandardized coefficients of .219 and .153, t-value of 1.847, and p-value of .065 (non-significant).

The overall result was that teachers 'belief and instructional practices variables agreed with rejecting the null hypothesis supported the alternative hypothesis. Therefore, an exogenous variable significantly influences communicative competence, while the oral proficiency variable has no significant correlation. An R2 of .381 indicated $38.1 \%$ of differences in communicative competence attributed to teachers 'beliefs, instructional practices, and teachers' oral proficiency. This means $61.9 \%$ of the variation of communicative competence was attributed to another variable not covered in this study. Moreover, the table presents three exogenous variables, which teachers believe had the most significant contribution to which the result was obtained $($ Beta $=$ 
$.466, \mathrm{P}$-value $=.000)$ followed by instructional practices that acquired $($ Beta $=.223, \mathrm{P}$-value $=.044)$ and the last was the oral proficiency of teachers with acquired $($ Beta $=.219$, P-value $=.065)$.

The direct influence of the non-independent variable serves as a predictor that the variables and non-dependent variables can intervene to traverse one or more variables. Table 6 shows that the latent variable between the indicators affected the endogenous research skill $(\mathrm{p}<0.05)$ by causing regression in teachers' beliefs, instructional practices, and oral proficiency.

According to the study Goh and Burns (2012), such issues impede learners' progress toward improving their oral fluency and accuracy, necessitating teachers to develop teaching strategies that enable learners to demonstrate mastery of basic English skills at the elementary level. In language classrooms, teachers must explicitly teach speaking to motivate students to use the target language. The target language is used to create a dynamic skill situation. This means that simply providing learners with speaking activities is not the same as teaching them the necessary knowledge, skills, and strategies for speaking. According to Gomez (2019), this does not mean that oral proficiency cannot be acquired even when it is not used frequently, such as at home or in social situations.

Additionally, the most common speaking difficulties are with grammar, the art of questioning, redundancy, fluency, and thought organization. Speaking development requires the teacher's intervention and guidance. It provides teachers with a framework for reflecting on their current practices and expanding them for the benefit of both themselves and their students. Based on the study of Burns (2016), which entails concurrent processes that require the speaker's knowledge and abilities to be activated in real-world speaking.

However, specific findings from Farrell and Bennis (2013) support teachers' beliefs can influence their teaching practices and language instruction in the classroom. They have the potential to influence teaching processes, classroom decision-making, and the implementation of a teaching approach, all of which can affect teacher development and student learning performance.

\section{Most Appropriate Model of Communicative Competence in the Filipino Language}

This section reflects the final research question to determine the model most appropriate to the variables as a predictor of communicative competence in the Filipino language of teachers. Table 1 must need to be modified to comply with the needs of the goodness of fit measures. Table 7 summarizes the five models developed in this study.

\section{Table 7}

In determining the most appropriate model, all indexes should be within an acceptable range. The Chi-square/degrees of freedom value must be between 0 and 2, with a corresponding p-value greater than or equal to 0.05. The Root Mean square of Error Approximately value must be less than 0.05 and have a corresponding p-close value greater than or equal to 0.05 . Other indexes such as the Normed Fit Index, Tucker-Lewis Index, Comparative Fit Index, and Goodness of Fit Index must be higher than 0.90.

Table 7

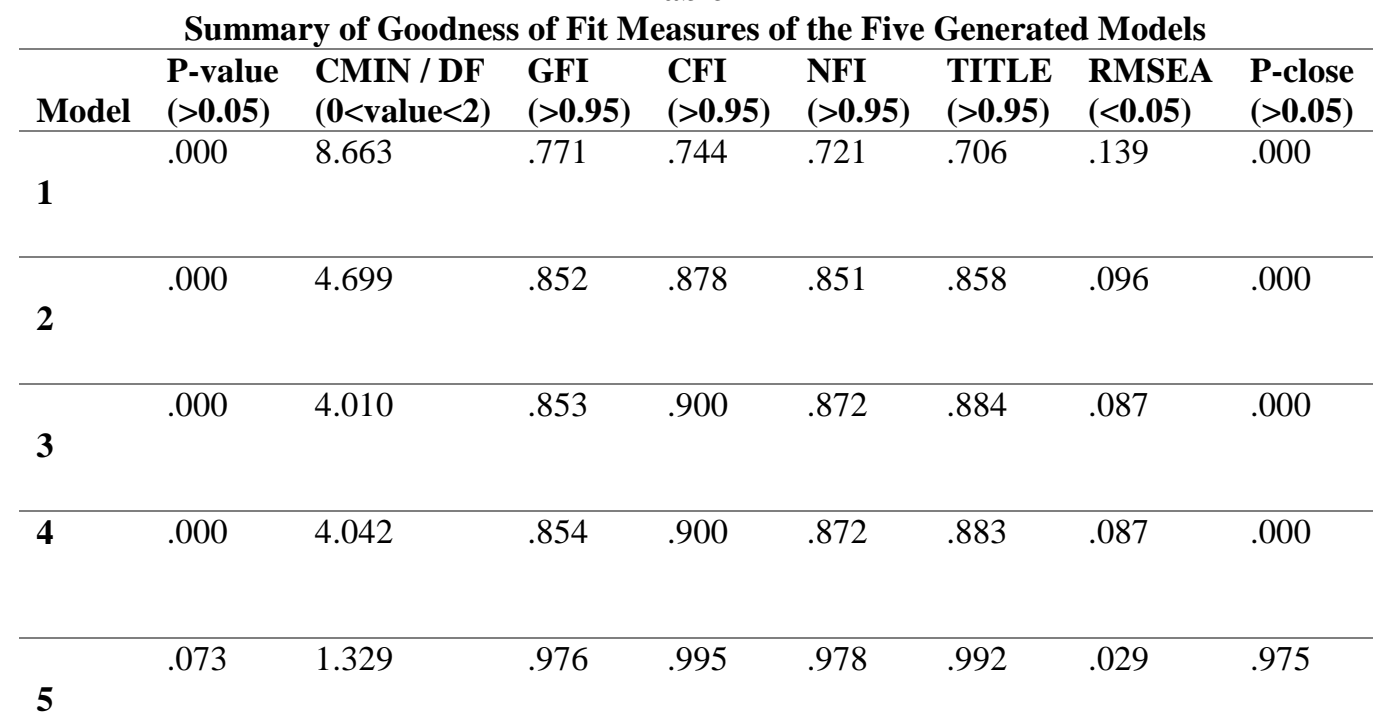

Legend: CMIN/DF - Chi-Square/Degrees of Freedom GFI - Goodness of Fit Index

RMSEA - Root Mean Square of Error Approximation
NFI -Normed Fit Index

TLI -Tucker-Lewis Index

CFI - Comparative Fit Index

The generated Structural Model 1 shows the direct causal relationship of exogenous variables: teachers 'beliefs, instructional practices, and oral proficiency. The framework model of Table 1 needs modification to respond to the needs of the goodness of fit measures. In turn, this model is inappropriate because $\mathrm{p}$-value $=.000$; RMSEA $=.139$ and with $\mathrm{p}$-value $=.000$ all index values has not met the demands of each premise. 
Finally, the generated Structural Model 5 showing the direct causal correlation of exogenous variables: teachers 'beliefs, instructional practices, and oral proficiency was identified as the most appropriate model. The most appropriate model is quite acceptable, as shown in Table 7. Chi-Square divided by degrees of freedom is 1.329 with a P-value of .073. This indicates the most appropriate model. This is supported by the Root Means Square of Error Approximation index of .029, which is less than the 0.05 significance level with a related P-close of .975. Also, other indexes such as the Normed Fit Index, Tucker-Lewis Index, and Comparative Fit are highly indicative of the most appropriate model because all measurements are derived from the criteria. In total, table 8 shows the direct effects described by the arrows from the predictor variable presented on the left side to the right side where the non-independent variable did not pass through the other variable.

Indirect effects are the correlation of the predictor of the variable and the non-independent variable that may mediate one or more variables. Presented in table 9 the effect of the latent variable and between the indicators, the latent variable was estimated to generate regression in teachers' belief, instructional practices, and oral proficiency of teachers significantly affect the endogenous variable communicative competence $(\mathrm{p}<.05)$.

To summarize, only the fifth of the five structural models discovered contains a marker indicating exceptional fit to the data; it has been designated as the most appropriate structural model. The research is based on constructivism theory, which establishes a theoretical framework for communicative competence on the premise that learning is collaborative and that social interaction is critical for cognitive development. This conclusion is supported by Stenberg's (2008) study, which states that learning is a collective mental construction through collaboration. Faryadi's (2015) study also states that collaboration facilitates learning.

\section{SUGGESTIONS}

The researcher proposed the following recommendations based on study findings: teachers' beliefs', instructional practices, oral proficiency, and communicative competence in the Filipino language.

First, focus on increasing teachers' belief, especially in error correction and assessment, the only indicator that achieved a high descriptive level. This will be accomplished by developing teachers' communicative skills and enhancing their use of a variety of teaching strategies. This will allow students' knowledge to be expanded and their abilities and skills shaped. Concentrate on education as a school administrator because it is the bedrock of everything. Allocate a sizable budget for sending teachers to various training sessions because they will significantly contribute to the field of education. Additionally, knowledge sharers teachers continue to improve instruction to develop the skills that students should acquire. Develop strategies, activities, and methods to develop these abilities to enhance students' communicative and learning capabilities.

Second, focus on improving teachers' instructional practices, particularly instructional strategies that emphasize student comprehension, group work, speaking skills, and instructional strategies. According to the most appropriate model, it affected the endogenous variable. This will be accomplished by emphasizing the importance of teachers developing their capacity to develop skills that will benefit students. Teachers' interactions with their students' personas by comprehending, supporting, and monitoring their learning greatly benefit students. Strengthen classroom activities and maintain open communication with students, parents, and prospective parents to better understand students' overall needs. School administrators must enhance teachers' and student managers' professional development through attendance at seminars and training for all teachers (whether beginner or older). They are organizing a gathering or expressing distress with school personnel.

Thirdly, to enhance the oral proficiency of Filipino teachers, particularly in the areas of comprehension, fluency, vocabulary, proper pronunciation, grammar, classroom instruction, and non-verbal communication. This will be given increased importance and attention to develop further the skills that will serve as the foundation for future learning expansion. This should be continued to assist teachers in further developing their oral proficiency. Teaching will be enhanced further with teachers who share their knowledge to help students develop their acquired skills. They can develop strategies, activities, and methods to ensure that these abilities are developed to help students' abilities and learning expand. For school administrators, intensify the development of policies, guidelines, and planning and train teachers to improve their knowledge of the Filipino language. The most appropriate model confirms that teachers' beliefs and instructional practices are the most effective predictors of Filipino teachers' communicative ability, implying that teachers' communicative ability develops due to their beliefs and instructional skills being evaluated and valued. Activities at the level of Filipino teachers' communicative competence.

\section{CONCLUSION}

The study was conducted using a structural model, which included a thorough analysis of the results using statistical methodology. Additionally, the researcher's actions are consistent with the study's requirements. The study's findings indicated a significant relationship between teachers' beliefs, instructional practices, and oral proficiency in terms of communicative competence. The study's findings indicated that Filipino teachers have a very high belief in themselves, their instructional practices, oral proficiency, and communicative competence. This means that teachers must be aware of their own beliefs, instructional practices, and oral proficiency to develop adequate communicative competence.

However, the study discovered that only two variables significantly affect Filipino teachers' communicative competence: beliefs and instructional practices. Table 6 demonstrates that teachers' oral proficiency is non-significant, with standardized and unstandardized coefficients.219 and.153, at-value of 1.847 and a p-value of.065 respectively. Thus, teachers' beliefs and instructional practices variables corroborated the null hypothesis's rejection and favored the alternative. As a result, an exogenous variable significantly affects communicative competence, whereas the oral proficiency variable does not. According to Gomez 
(2019), this does not mean that oral proficiency cannot be attained even when oral communication is not used frequently, such as at home or in social situations.

Additionally, the most common speaking difficulties are with grammar, the art of questioning, redundancy, fluency, and thought organization. Speaking development requires the teacher's intervention and guidance. It provides educators with a framework for reflecting on current practices and expanding them for the benefit of both themselves and their students (Burns, 2016).

Further, only the fifth of the five discovered structural models contains a marker indicating exceptional fit to the data; it has been identified as the most appropriate structural model, as presented in Table 7. The research is based on constructivism theory, which establishes a theoretical framework for communicative competence on the premise that learning is collaborative and that social interaction is critical for cognitive development. Constructivists believe that knowledge is acquired through adaptation to one's environment. One reshapes acquired knowledge and creates new knowledge in the process (Sternberg, 2008). Thus, learning is a collective mental construction. Collaboration facilitates learning in the constructivist classroom (Faryadi, 2015).

Additionally, as a proposal to the study, the researchers suggested Project-based Learning (PjBL), a constructivist teaching strategy that entails an extended period of knowledge exploration. JPL provides numerous opportunities for learners to practice constructively using the target language at numerous stages, most notably through group discussions and collaboration on a project (Papanikolaou \& Boubouka, 2010).

\section{REFERENCES}

1. Ahmed, S. T. S. \& Pawar S. V. (2018). Communicative Competence in English as a Foreign Language: It is Meaning and the Pedagogical Considerations for its Development. The Creative Launcher. 2(6). 301-312.

2. Baridalyne, N. (2012). Sampling, Sample size estimation, and Randomisation. Indian Journal of Medical Specialities. 2012;3:195-197.

3. Bentler, P. \& Savalei, V. (2010). "Analysis of correlation structures: Current status and open problems." In S. Kolenikov, D. Steinley, \& L. Thombs (Eds.), Statistics in the Social Sciences (2010):(pp. 1-36).

4. Burns, A. (2016). Teaching speaking: Towards a holistic approach.

5. Celik, H., \& Yilmaz, V. (2013). Structural Equation with Lisrel 9.1 Modeling. Ankara: Ani Publishing. 61-73.

6. Creswell, J. (2013). Research design: Qualitative, quantitative, and mixed methods approach 4th Edition (4th edition). Thousand Oaks: SAGE Publications, Inc.12

7. Farrell, T. S. C., \& Bennis, K. (2013). Reflecting on ESL teacher beliefs and classroom practices: A case study. RELC Journal, 44(2), 163-176.

8. Faryadi, Q. (2015). Teaching Philosophy Statements. IOSR Journal Of Research \& Method In Education (IOSR-JRME). Volume 5, Issue 6 Ver. III PP $61-66$

9. Gomez, Abigail. (2019). Oral Proficiency Assessment of Pre-Service Teachers of a Public University in the Philippines. 10.13140/RG.2.2.20248.85764.

10. Goh, C.C.M. \& Burns, A. (2012). Teaching speaking: A holistic approach. New York: Cambridge University Press.

11. Gudu, B. O. (2015). Teaching Speaking Skills In English Language Using Classroom Activities In Secondary School Level In Eldoret Municipality, Kenya. Journal Of Education And Practice, Vol.6, No.35, 55-63

12. Hatami, R. (2018).Development of a protocol for environmental impact studies using causal modeling. Water Res. 138, 206-223.

13. Johnson, B. \& Christensen, L. (2004). Educational Research: Quantitative, Qualitative and Mixed Approaches (2nd ed). Needham Heights, MA: Allyn\& Bacon.

14. Karagöz, Y. (2016). SPSS ve AMOS 23 Uygulamall Istatistiksel Analizler. Ankara: Nobel.

15. Khan, A., Khan, S., Islam, S. U., \& Khan, M. (2017). Communication Skills Of a Teacher And Its Role In The Development Of the Students' Academic Success. Journal Of Education And Practice, ISSN 2222-1735. 8(1), 18-21.

16. Leedy, P. \& Ormrod, J. (2001). Practical research: Planning and design (7th ed.). Upper Saddle River, NJ:

17. Li, X. (2012). The Role of Teachers' Beliefs in the Language Teaching-Learning Process. Theory and Practice in Language Studies, 2(7), 1397-1402.

18. Maley, A. (2009).Creative Writing For Language Learners And Teachers. Retrieved on June 30, 2012, from http://www.teachingenglish.org.uk/think/articles/ creative-writing-language-learners-teachers

19. Papanikolaou, K., \& Boubouka, M. (2010). Promoting Collaboration in a Project-Based E-Learning Context. Journal of Research on Technology in Education, 43(2), 135-155.

20. - Teachers' beliefs about communicative

20. Tootkaboni, A. (2019). "Teachers' beliefs and practices towards communicative language teaching in the expanding circle." Allameh Tabataba'i University, 52(100):265-289.DOI:10.4067/S0718 09342019000200265

21. Sternberg, R. (2008). Applying Psychological Theories to Educational Practice. American Educational Research Journal, 45 (1), 150166.

22. Ullman, J. (2006). "Structural equation modeling." In B. G. Tabachnick \& L. S. Fidell (Eds.), Using multivariate statistics, (5th ed.;(2006) pp. 653-771). Boston: Allyn \& Bacon

23. Webb, N. M., Franke, M. L., Ing, M., Wong, J., Hernandez, C. H., Shin, N., \& Turrou, A. C. (2014). Engaging With Others' Mathematical Ideas: Interrelationships Among Student Participation, Teachers' Instructional Practices, And Learning. International Journal Of Educational Research. Vol. 63, pp. 77-93

24. Yufrizal, H. (2017, July 26). Teachers And Students' Perception of Communicative Competence In English As a Foreign Language In Indonesia. Academic Journals. Vol. 12(17), pp. 867-883

25. Zheng, H. (2009). A Review of Research on EFL Pre-Service Teachers' Beliefs and Practices. Journal of Cambridge Studies, 4(1), 7381. 